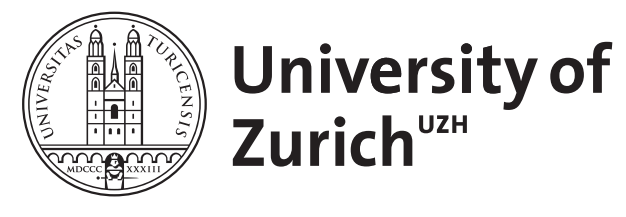

\title{
Reported happiness, fast and slow
}

Studer, Raphael ; Winkelmann, Rainer

\begin{abstract}
The paper uses paradata on response time, cognitive effort and questionnaire order from a large Dutch internet panel survey to study the association between reporting process and reported happiness. We find that slower responses and higher self-stated cognitive effort are associated with lower reported happiness, potentially, because they proxy for momentary mood. Moreover, in multivariate happiness equations, these factors moderate the estimated effect of income on happiness, while no interaction effects are found for other socio-economic determinants of happiness. Our findings have implications for the interpretation of relative marginal effects in economic happiness equations.
\end{abstract}

DOI: https://doi.org/10.1007/s11205-013-0376-x

Posted at the Zurich Open Repository and Archive, University of Zurich ZORA URL: https://doi.org/10.5167/uzh-79440

Journal Article

Accepted Version

Originally published at:

Studer, Raphael; Winkelmann, Rainer (2014). Reported happiness, fast and slow. Social Indicators Research, 117(3):1055-1067.

DOI: https://doi.org/10.1007/s11205-013-0376-x 


\title{
Reported happiness, fast and slow*
}

\author{
RAPHAEL STUDER \\ RAINER WINKELMANN \\ University of Zurich \\ University of Zurich, and IZA
}

June 2013

\begin{abstract}
The paper uses paradata on response time, cognitive effort and questionnaire order from a large Dutch internet panel survey to study the association between reporting process and reported happiness. We find that slower responses and higher self-stated cognitive effort are associated with lower reported happiness, potentially, because they proxy for momentary mood. Moreover, in multivariate happiness equations, these factors moderate the estimated effect of income on happiness, while no interaction effects are found for other socio-economic determinants of happiness. Our findings have implications for the interpretation of relative marginal effects in economic happiness equations.
\end{abstract}

JEL Classification: I31

Keywords: paradata, response time, happiness, mood

${ }^{*}$ Corresponding author: Rainer Winkelmann, University of Zurich, Department of Economics, Zurichbergstrasse 14, CH8032 Zurich, email: rainer.winkelmann@econ.uzh.ch. Acknowledgments: The paper owes many insights, as well as its title, to Kahneman (2011). We are grateful to two anonymous reviewers, as well as participants at the EEA annual congress, the MESS workshop and the HUI and Sinergia seminars for helpful comments and suggestions. Particular thanks go to Bert van Landeghem, Bruno Frey, Arie Kapteyn, Arthur Stone and Josef Zweimüller. Financial support from the Candoc Forschungskredit of the University of Zurich is gratefully acknowledged. The paper uses data of the 2011 wave of the LISS panel of CentERdata. 


\section{Introduction}

This paper uses paradata to gain a better understanding of the validity of survey responses to happiness questions and findings from happiness regressions. Happiness, as defined in this paper, is the degree to which one evaluates one's life-as-a-whole positively (Diener, 1984, Veenhoven, 1984), and we consider the single-item question "All things considered, how happy would you say you are?" (on a scale from 0 to 9 ). Paradata is a term coined by Couper (1998) for information pertaining to the process of collecting survey data through computer-assisted modes. Typical examples include keystroke data capturing the navigation through the questionnaire, and, importantly, time stamps.

The main application of paradata so far has been for survey development and quality management, including analyses of item-nonresponse, general measurement error, and attrition (see, e.g., Couper and Kreuter, 2013, Durrant et al., 2013). This is in contrast to decades of research in psychology, where the response process itself, and response times in particular, have been fundamental to the study of cognitive processes. More recently, there is some convergence between the two research areas, as survey paradata are increasingly related to substantive behavioral and psychological questions. An example is the use of response time to reveal hidden biases through the implicit association test (Banaji and Greenwald, 2013) that has been implemented in the German Socio-Economic Panel (Dietrich et al., 2013).

Our paper follows a related approach and studies the association between answers to the happiness question and the response process, as captured by available paradata. We employ survey data from the 2011 wave of the Dutch Longitudinal Study for Social Sciences (LISS), an internet suvey that was initiated in 2007 with more than five thousand participating households. Apart from the happiness response and standard socio-demographic and economic characteristics, we have information on three para-variables: "response time", "questionnaire order", and "self-assessed cognitive effort". Response time is simply the time between display of a question and entering of the response. Within a given session, some respondents are shown a link to more than one questionnaire, and we can use time stamps to determine the order in which they were opened. Finally, participants are asked about the extent to which the happiness question "made them think". While elicited in conventional mode, this question relates to the data collection process as well.

The analysis is guided by three research questions that have, to the best of our knowledge, not been 
addressed before. First, we ask whether paradata can be used to predict levels of reported happiness. Second, we investigate whether the measured effects of socio-economic characteristics interacts with the reporting process, in the context of regression models with reported happiness as dependent variable. Third and finally, we explore possible explanations why aspects of the reporting process could be associated with reported happiness. In particular, we hypothesize that the happiness response and its correlates may depend on whether the response process leans more heavily on intuitive System 1 thinking rather than reasoned System 2 thinking (see Kahneman, 2011). In this view, individual variation in paradata, i.e., longer response time, responding to the happiness question after having gone through a background questionnaire, and high self-assessed cognitive effort are all proxies for a likely activation of System 2 thinking when responding to the happiness question.

Our research thus relates to earlier studies that have emphasized the power of transient influences and System 1 thinking on reported happiness (Schwarz, 1987, Schwarz and Clore, 1983, Strack, Martin and Schwarz, 1988). This research is often cited, together with low test-retest stability (Krueger and Schkade, 2008), when pointing out the limited usefulness of subjective happpiness indicators (e.g., Betrand and Mullainathan, 2001). The underlying assumption is that happiness responses are more likely valid and stable indicators of "true" happiness, i.e., a positive evaluation of one's life-as-a-whole, if System 2 thinking is active during the response process. If so, and assuming that paradata are indeed valid proxies for System 2 thinking, our approach has the potential for improving future happiness research, as paradata are becoming increasingly available and can then be used to control for response type.

The remainder of the paper is structured as follows: data collection, sample and variables are described in Section 2. In Section 3, we introduce the reporting function as a conceptual framework for capturing the effect of paradata on stated happiness. Our results in Section 4 suggest that the reporting process correlates with levels of reported happiness and moderates the estimated associations with socio-economic determinants. For instance, paradata affect the trade-off ratio between income and unemployment. We discuss one particular theoretical framework that can explain our results. Section 5 concludes with implications for ongoing happiness research. 


\section{Data}

\subsection{Happiness questionnaire}

We use data from a monthly internet panel, the Longitudinal Study for Social Sciences (LISS). The LISS panel is a general purpose household survey that collects comprehensive information on income, employment, education, social participation and attitudes, among others. The panel survey is run by CentERdata, based at Tilburg University in the Netherlands. It was started in 2007, when 10'150 addresses were randomly drawn from the Dutch population register and 5176 households initially agreed to participate in the survey (see Scherpenzeel, 2009, for further details). Following a refreshment sample stratified by age, ethnicity and household types in 2009 the LISS panel has been shown to be representative for the Dutch population (de Vos, 2010).

The analysis of this paper is based on a happiness module that was in the field during March and April of 2011. We have 4399 valid responses of individuals participating either in the March or April wave. The happiness questionnaire consisted of four consecutive screens. The appendix shows the screenshots. The first page tells participants that only one question will be asked. The second page displays a usual single item happiness question. Participants answered the question "All things considered, how happy would you say you are?" on a Likert scale ranging from 0 to 9 . Next, on the third page of the questionnaire, respondents were invited to evaluate the happiness question by assessing difficulty in answering, clarity of the question, and degree of thought provocation. On the last page participants were offered the possibility to write a comment. Only 35 individuals did so.

- — - Table 1 about here — - -

Furthermore, we have information on a participant's age, gender, income, employment and marital status, education, household composition and country of origin. Means and standard deviations of reported happiness and background variables employed in this study are shown in Table 1. The average happiness is 7.15 on the $0-9$ scale. The employment rate is 52 percent, and as the average age of 51 indicates, the sample contains a sizeable proportion of retired individuals. 


\subsection{Reporting variables}

At the beginning of each month the LISS participants receive an electronic message including web links directing to different question modules. Participants can freely choose at which day and time or in which order they want to respond to the question modules. The LISS mechanically collects time stamp data on the interaction between the user and the underlying database. Thus, it is known for example, at what time a particular question module or question was opened and when an answer was sent back. Moreover, as stated above, participants self-assess their reporting behavior on page 3 of the happiness questionnaire. We use these paradata to construct three reporting variables.

Figure 1 shows a kernel estimate of the distribution of response times in seconds, using an Epanechnikov kernel with bandwidth equal to 0.6. Response times vary substantially, although $50 \%$ of all individuals answered the happiness question within 8 seconds. The minimum answer time was 2 seconds and the maximum 97 seconds. The average is 10 seconds, which is similar to the average reported by Couper et al. (2006) for other rating questions. It is unlikely that variation in response times is related to varying speed of the internet connection, as the LISS panel offers broadband internet connections to all participating households (Scherpenzeel, 2009).

- - Figure 1 about here - - -

A possible explanation for variation in response times is reading speed. Reading speed may also correlate with (observed and unobserved) determinants of happiness. We therefore obtained adjusted response times by computing deviations from predicted times. Predictions are obtained from an exponential regression model (i.e., constant hazard duration model), using a large set of socio-economic and socio-demographic variables as predictors. Estimated marginal effects are shown in Table 2. Older people and foreigners tend to answer more slowly, whereas employed, married and better educated participants respond faster on average. Not surprisingly, respondents with self-stated difficulties in answering the happiness question responded slower, on average, than others. Adjusted response time is then the residual of this first stage regression, a positive value if a person was slower in answering the happiness question than a typical person with similar characteristics, and a negative value otherwise. We interpret this adjusted time as a proxy variable for the amount of thinking, or deliberate cognitive effort, individuals put into answering the question. 
The questionnaire contains a second reporting variable related to cognitive effort, a self-evaluation of respondents about the answering process. In particular, page three of the questionnaire included the question: "Did the (happiness) question get you thinking about things?". The answer scale went from 1 (="totally disagree") to 5 (="totally agree"). More than $20 \%$ of the respondents completely disagreed with this statement, and about $12 \%$ disagreed. We construct a dichotomized version of this variable, "cognitive effort", taking the value 0 if a respondent either disagreed or strongly disagreed, and the value 1 else. Of course, this is not an objective measure of cognitive effort but rather subjective and self-assessed. Also, by its very nature it is limited to the conscious dimension of effort. This question has been included by LISS originally for the purpose of questionnaire development. We are not aware of any prior research using this information in the context of happiness equations.

The third reporting variable captures the context of the answering process. The LISS panel sends a monthly Background Variable Questionnaire (BVQ) to the contact person of the household. We compared the activation time of the BVQ to that of the happiness questionnaire. The third reporting variable takes the value 1 if the BVQ was opened by the contact person during the two hours preceding the happiness questionnaire. It is zero otherwise. Ones are observed in about $23 \%$ of all cases. There are a number of possible explanations why there can be an effect on reported happiness. One is salience of the information that was provided in the BVQ. The other is the effect on response burden which markedly increases for those who chose to answer the BVQ first. For example, Galesic and Bosnjak (2009) have shown that respondents change their response behavior (faster responses and less variation) with increasing time spent on a questionnaire.

\section{Models}

In this section, we provide a formalized model of the reporting process, in order to clarify how reported happiness may depend on reporting variables obtained from paradata, in addition to standard socioeconomic characteristics. As in Oswald (2008) and Oswald and Wu (2011), we start from the notion of a potential discrepancy between reported happiness and "true" happiness, and a reporting function that describes the relationship between the two. The ultimate object of interest, here as in most social science 
applications, are the (causal) effects of socio-economic determinants, such as income or unemployment, on true happiness (e.g., Frey and Stutzer, 2002).

Our framework allows us to distinguish between two cases, one in which reporting variables are ignorable, due a separable reporting function, and a second one, where this is not the case. Under a strong version of ignorability, reported happiness effects and true happiness effects coincide; under a weaker version, only ratios of effects coincide. With effect heterogeneity, due to a reporting process that moderates the estimated effects, one can instead focus on the set of estimated effects that correspond to a certain response mode, e.g. System 2 thinking.

\subsection{Reporting function}

Let true happiness be a function of $k$ external factors: $H=h\left(x_{1}, \ldots, x_{k}\right)$. The functional form of $h$ remains unspecified, but we assume that the derivative of the function exists in each point of its domain and therefore $h$ is continuous in its $k$ arguments. Moreover, let reported happiness $R$ be given by the differentiable function

$$
R=r\left(x_{1}, \ldots, x_{k}, z_{1}, \ldots, z_{m}\right)+\varepsilon
$$

where $z_{1}, \ldots, z_{m}$ denote reporting variables and $\varepsilon$ captures the influence of transient influences, assumed to be independent of reporting variables and happiness determinants. Given model (1), with possible interactions between $x_{j}$ and $z_{l}$, it will be the case that $\partial H / \partial x_{j} \neq \partial R / \partial x_{j}$, and the marginal rates of substitution, and trade-off ratios, differ for $H$ and $R$. However, suppose instead that (1) can be re-written as

$$
R=r\left(h\left(x_{1}, \ldots, x_{k}\right), z_{1}, \ldots, z_{m}\right)+\varepsilon
$$

This is a special case of (1), where $x_{j}$ affects reported happiness only through $h\left(x_{1}, \ldots, x_{k}\right)$ and it is assumed that $r$ is monotonically increasing in $h$. Model (2) implies that $z$ does not affect the ratio of marginal effects, since

$$
\frac{\partial R / \partial x_{i}}{\partial R / \partial x_{j}}=\frac{\partial R / \partial H \cdot \partial H / \partial x_{i}}{\partial R / \partial H \cdot \partial H / \partial x_{j}}=\frac{\partial H / \partial x_{i}}{\partial H / \partial x_{j}}
$$

Under model (2), reported happiness identifies the relative marginal effect of true happiness. Under model (1), this is not the case, as the reporting process drives a wedge between true and reported happiness that 
distorts relative effects. Below, we will test model (2) against the more general model (1). If the reporting function (2) cannot be rejected, then we know that the difference between reported and true happiness is unimportant, as long as conclusions focus on relative effects of true happiness. Note that in this framework, it is not sufficient to assume that $r$ in (2) is the identity function, in order to identify marginal effects for true happiness. In addition, the reporting function would need to be separable in $h\left(x_{1}, \ldots, x_{k}\right)$ and $z$ as well.

\subsection{Empirical model}

A linearized version of model (2) can be obtained by specifying the arguments of both functions to form an additive index and assuming the simplest functional forms for $h$ and $r$, the index function. In order to test model (1) against model (2) empirically, a set of interaction effects between $x$ and $z$ is added. The linear empirical model reads:

$$
R=x^{\prime} \beta+z^{\prime} \gamma+(z x)^{\prime} \delta
$$

where $\delta$ captures interaction effects. The effect of socio-economic background variables on reported happiness is a function of reporting variables as long as $\delta \neq 0$. For instance, with $z$ being the adjusted response time and $x$ income, $\beta>0$ and $\delta<0$ would imply that the marginal effect of income on reported happiness is higher when the answer is given more slowly. In other words, respondents would attribute less weight to income if they take more time to answer. Hence, it depends on $\delta$ whether the reporting function has the form of model (1) or model (2). If $\delta$ is a multiple of $\beta$, relative marginal effects with respect to components of $x$ are unchanged by $z$, giving rise to model (2). Otherwise, model (1) is obtained.

Since $R$ is logically restricted to lie between 0 and 9 , it is impossible to observe negative mean values $E(R \mid x, z)$, or values above 9 . This consideration would be ignored by a linear regression model. Hence we specify a non-linear regression model whereby

$$
R=f\left[x^{\prime} \beta+z^{\prime} \gamma+(z x)^{\prime} \delta\right]+v
$$

$f$ is a transformation function that maps the real line onto the $[0,9]$ interval, and $E(v \mid x, z)=0$. A simple approach is to use the logistic cumulative distribution and multiply it by factor 9 . The resulting model has a conditional expectation function that accounts for the boundedness of the dependent variable. In 
comparison to the ordered logit model, this specification is more parsimonious and the results are easier to interpret. Marginal effects differ from individual to individual due to the non-linearity. As a rule of thumb, average marginal effects can be obtained by multiplying the coefficient with the factor $\bar{R}\left(R^{\max }-\bar{R}\right) / R^{\max }$, where $\bar{R}$ is mean reported happiness in the sample. In our data, this factor is approximately equal to 1.5. Following Papke and Wooldridge (1996), who developed this approach for fractional data, we estimate the model by Bernoulli quasi maximum likelihood.

\section{Results}

We first use our data to estimate a happiness equation without including reporting variables. $x$ includes socio-economic individual determinants of happiness that are commonly used in the economic well-being literature (e.g., Frey and Stutzer, 2002). Estimates of the parameter vector shown in column 1 of Table 3 replicate standard findings. Reported happiness is positively associated with income, marriage and employment. Men and foreigners report lower happiness and happiness scores are U-shaped in age. The magnitude of the associations are similar to earlier findings as well. For instance, a 1\% raise in income is associated with an increase of reported happiness by 0.4 points on average.

\section{— — Table 3 about here — - -}

Columns 2 to 4 in Table 3 add one reporting variable at a time to the regression, assuming the absence of interaction terms (i.e., $\delta=0$ ). Table 3 provides evidence that reporting variables do correlate with levels of reported happiness, ceteris paribus. For instance, based on column (2), an increase in adjusted response time by 12 seconds is associated with an approximately 0.1 point lower reported happiness. A difference of similar magnitude results when comparing respondents with a cognitive effortful answer and those without. These associations might look small at first. However, if compared to effects of other socioeconomic characteristics, they are actually quite large. For instance, they are larger in absolute value than the impact of being employed versus non-employed (this includes unemployment and non-participation). The last column of Table 3 reports a positive association of questionnaire order with reported happiness. Those, who reviewed the background questionnaires first report a higher happiness, on average. Another noteworthy feature of the results in Table 3 is that the estimated parameter vector for the socio-economic 
determinants is relatively insensitive to the inclusion of reporting variables. Hence, a regression of reported happiness on individual characteristics excluding reporting variables seems not to suffer from omitted variable bias.

Results shown in Table 4 refer to the unconstrained empirical model (5). The estimates tell us whether reporting circumstances change the estimated relationship between happiness and these socio-economic characteristics, and in particular, whether relative marginal effects change (i.e., the distinction between reporting function (1) and (2)). The upper panel of the table reports estimates of the main effects of happiness determinants $(\hat{\beta})$. The lower part of the table displays the main effect of the reporting variables together with the estimated interaction coefficients $\hat{\delta}$. For the sake of exposition, the Table includes only part of the socio-economic coefficients and interaction parameters, although the models were estimated with the same set of variables that were used in Table 3 (not shown are the main effects and interactions of age, age ${ }^{2}$, male, foreigner, log number of household members, and April interview).

\section{— - - Table 4 about here — - -}

Again, the analysis is done separately for the three variables. Column 1 of Table 4 shows the results for the happiness equation that is interacted with response time. All but one of the interaction terms are close to zero and statistically insignificant. The exception is the effect of income on reported happiness that is found to decrease with response time. For instance, the average marginal effect of a $1 \%$ income increase increases by 0.04 points, or $15 \%$, if the response time is reduced by 10 seconds. An even stronger interaction effect of income is found in column 2 of Table 4, where the marginal effect of a $1 \%$ income increase is more than twice as large for those individuals who stated that answering the question required no cognitive effort, as opposed to others.

The last column of Table 4 shows results for the questionnaire order variable. It is conceivable that answering the socio-economic questions increases the salience of these variables, leading to a stronger observed relationship. Also, questionnaire order might lead to priming (Strack at al., 1988), whereby participants substitute answers given to previous questions, for instance about their income or employment status, for the assessment of happiness. However, we cannot find any evidence for such an effect in our data. 
Summarizing the evidence, we find a statistically significant interaction effect in the model (2) regressions, but only for income and only for response time and cognitive effort. Specifically, slower and more thoughtful answers reduce the happiness-income gradient. Since the evidence suggests therefore a non-proportional moderation of the income effect relative to the effects of other socio-economic characteristics on happiness, marginal rates of substitution, or trade-off ratios, might not be invariant to response behavior.

\section{A possible explanation}

Suppose, that our reporting variables indeed proxy for System 1 and System 2 thinking, as conjectured in the introduction. As a general happiness question is of an evaluative nature, one would expect that those who think longer about their answer and also state that they spent more cognitive effort, are the same individuals, for which the happiness answers are less random and for whom one finds stronger relationships to the socio-economic determinants. However, our evidence does not support this hypothesis.

A possible resolution to this "puzzle" is an alternative view, whereby reporting variables, and the response time in particular, do not primarily relate to the amount of cognitive deliberations when answering the question, but rather proxy for mood (e.g., Frederick, 2005; Kahneman, 2011). People in a good mood are more likely to answer spontaneously and intuitively, while people in a bad mood are more likely to rely on effortful mental activities when answering a question.

Such an association between mood and response process could explain the finding that slower respondents, as well as those exerting more cognitive effort, report lower levels of happiness. In this interpretation, the reduced happiness does not result from the higher effort per se, but rather from the indirect assocatiuon between high effort and worse momentary mood which is otherwise unobserved and not captured by the model. It also appears that a negative mood reduces the weight that individuals give to income changes when thinking about their happiness. The reason for this phenomenon is less clear and remains an interesting question for future research. 


\section{Conclusions}

When asked to respond to a survey question on how happy a person is with his or her life, some people respond quickly and some take more time to respond. Some people say that the happiness question got them thinking, while others don't. The objective of this paper was to explore whether these circumstances of reporting are associated with reported happiness, using data from a Dutch internet panel. There were two main findings on response time. First, responding slowly is associated with a lower reported happiness. A possible explanation is that respondents in a positive mood are more likely to give intuitive and therefore faster, answers.

Second, the marginal effect of income on happiness decreases with response time. To illustrate the magnitude of this effect, we can compute the income compensation that is necessary in order to make a non-working person equally well off to an employed person in terms of reported happiness. For a person with an average response speed this estimated compensation amounts to $32 \%$ of the initial income. For

a person, who takes a standard deviation longer to answer, the estimated compensating income is $37 \%$ of the initial income.

Happiness research finds itself at a critical juncture, where there is an increasing demand to use results to inform and formulate policy interventions. A key promise of happiness research for such policy debates is that it allows to overcome the limitation of traditional cost-benefit analysis that everything has to be measured up in dollars. With the increasing availability of happiness data, it becomes possible, at least in principle, to value policy trade-offs in terms of their effect on happiness, well-being or utility. Some difficulties of this approach have been pointed out recently by Boyce and Wood (2011) who showed that trade-off ratios are not invariant to personality characteristics. Our paper adds a further possible limitation, as such measured trade-off ratios may not be invariant to the reporting process either.

\section{References}

Banaji, M.R. and A.G. Greenwald, 2013, Blindspot: Hidden Biases of Good People, Delacorte Press.

Bertrand, M. and S. Mullainathan, 2001, "Do People Mean What They Say? Implications for Subjective Survey Data", American Economic Review, 91, 2, 67-72.

Boyce, C. J. and A. M. Wood (2011), "Personality and the marginal utility of income: Personality interacts 
with increases in household income to determine life satisfaction", Journal of Economic Behavior $\&$ Organization 78, 183-191.

Couper, M.P., 1998, "Measuring survey quality in a CASIC environment", Proc. Surv. Res.Meth. Sect. Am. Statist. Ass., 41-49.

Couper, M.P. and F. Kreuter, 2013, "Using paradata to explore item level response times in surveys", Journal of the Royal Statistical Society: Series A (Statistics in Society), Vol. 176, Issue 1, 271-286.

Couper, M.P., R. Tourangeau, F. G. Conrad and E. Singer, 2006, "Evaluating the Effectiveness of Visual Analog Scales : A Web Experiment", Social Science Computer Review, 24, 227-245.

de Vos, K., 2010, "Representativeness of the LISS-panel 2008, 2009, 2010", http://www.lissdata.nl, last consultation 14.10.2011

Diener, E., 1984, "Subjective Well-Being", Psychological Bulletin 95, 542-575.

Dietrich, J., K. Schnabel, T. Ortner, A. Eagly, R. Garcia-Retamero, L. Krger and E. Holst, 2013, "Internalized Gender Stereotypes Vary Across Socioeconomic Indicators", SOEPpapers on Multidisciplinary Panel Data Research No. 558.

Durrant, G.B., J. D'Arrigo and F. Steele, 2013, "Analysing interviewer call record data by using a multilevel discrete time event history modelling approach", Journal of the Royal Statistical Society: Series A (Statistics in Society), 176, 251-269.

Frederick S., 2005, "Cognitive Reflection and Decision Making", Journal of Economic Perspectives, 19, $25-42$.

Frey, B.S. and A. Stutzer, 2002, "Happiness and Economics: How the Economy and Institutions Affect Human Well-Being", Princeton, Princeton University Press.

Galesic, M. and M. Bosnjak, 2009, "Effects of questionnaire length on participation and indicators of response quality in a web survey", Public Opinion Quarterly, 73, 349-360.

Kahneman, D. and A.B. Krueger, 2006, "Developments in the Measurement of Subjective Well-Being", Journal of Economic Perspectives, 20, 3-24.

Kahneman, D., 2011, Thinking, fast and slow, Farrar, Straus and Giroux, New York.

Krueger, B. and D.A. Schkade, 2008, "The Reliability of Subjective Well-Being Measures", Journal of Public Economics, 92, 1833-1845.

Oswald, A., 2008, "On the curvature of the happiness reporting function from objective reality to subjective feelings", Economic Letters, 100, 369-372. 
Oswald, A. and S. Wu, 2010, "Objective Confirmation of Subjective Measures of Human Well-Being: Evidence from the U.S.A.", Science, 327, 576-579.

Papke, L.E. and J.M. Wooldridge, 1996, "Econometric methods for fractional response variables with an application to 401(k) plan participation rates", Journal of Applied Econometrics, Vol. 11, Issue 6, 619-632.

Scherpenzeel, A., 2009, "Start of the LISS panel: Sample and recruitment of a probability-based Internet panel", http://www.lissdata.nl, last consultation 14.10.2011

Schwarz, N., 1987, Stimmung als Information: Untersuchungen zum Einfluss von Stimmungen auf die Bewertung des eigenen Lebens, Heidelberg: Springer Verlag.

Schwarz, N. and G.L. Clore, 1983, "Mood, Misattribution, and Judgments of Well-Being: Informative and Directive Functions of Affective States", Journal of Personality and Social Psychology, 45, 513-523.

Strack, F., L.L. Martin and N. Schwarz, 1988, "Priming and communication: Social determinants of information use in judgments of life satisfaction", European Journal of Social Psychology 18, 429442.

Veenhoven, R., 1984, Conditions of Happiness, D. Reidel, Dordrecht. 


\section{Tables}

Table 1: Descriptive statistics $(\mathrm{N}=4,399)$

\begin{tabular}{lcc}
\hline & Mean & Standard deviation \\
\hline Happiness & 7.15 & 1.19 \\
Log after-tax household income & 7.84 & 0.52 \\
Proportion employed & 0.52 & 0.50 \\
Proportion with higher education & 0.53 & 0.50 \\
Age & 51.00 & 16.97 \\
Proportion male & 0.47 & 0.50 \\
Proportion married & 0.59 & 0.49 \\
Proportion foreigners & 0.12 & 0.33 \\
Log HH members & 0.80 & 0.52 \\
Proportion interviewed in April & 0.48 & 0.50 \\
\hline
\end{tabular}

Source: Longitudinal Study for Social Sciences, 2011

Table 2: Exponential regression of response time on characteristics

\begin{tabular}{lll}
\hline & Marginal effect & Standard error \\
\hline Male & 0.183 & $(0.208)$ \\
Age & $0.098^{* * *}$ & $(0.008)$ \\
Log after-tax household income & -0.485 & $(0.455)$ \\
Log number of household members & 0.094 & $(0.379)$ \\
Houseownership & -0.493 & $(0.300)$ \\
Employed & $-1.212^{* * *}$ & $(0.275)$ \\
Secondary education & $-0.825^{* *}$ & $(0.365)$ \\
Tertiary education & $-0.979^{* *}$ & $(0.381)$ \\
Married & $-0.626^{* *}$ & $(0.305)$ \\
Cohabiting & 0.016 & $(0.483)$ \\
Separated & -0.327 & $(0.461)$ \\
Foreigner & $1.535^{* * *}$ & $(0.423)$ \\
Returned to the question & $3.126^{*}$ & $(1.795)$ \\
Difficulty in answering & $0.455^{* * *}$ & $(0.103)$ \\
April interview & 0.141 & $(0.207)$ \\
\hline
\end{tabular}

$N=4,399$

Heteroscedasticity consistent standard errors are presented.

$* * * / * * /$ significant at the $1 / 5 / 10$ percent level 
Table 3: Regressions of reported happiness on characteristics and reporting variables

\begin{tabular}{|c|c|c|c|c|}
\hline & (1) & $(2)$ & $(3)$ & (4) \\
\hline Response time & & $\begin{array}{c}-0.007^{* * *} \\
(0.002)\end{array}$ & & \\
\hline Self-assessed cognitive effort & & & $\begin{array}{c}-0.083^{* * *} \\
(0.026)\end{array}$ & \\
\hline Background questionnaire first & & & & $\begin{array}{l}0.056^{*} \\
(0.031)\end{array}$ \\
\hline Log after-tax household income & $\begin{array}{c}0.265^{* * *} \\
(0.030)\end{array}$ & $\begin{array}{c}0.265^{* * *} \\
(0.030)\end{array}$ & $\begin{array}{c}0.264^{* * *} \\
(0.030)\end{array}$ & $\begin{array}{c}0.267^{* * *} \\
(0.030)\end{array}$ \\
\hline Employed & $\begin{array}{l}0.078^{* *} \\
(0.032)\end{array}$ & $\begin{array}{l}0.078^{* *} \\
(0.032)\end{array}$ & $\begin{array}{l}0.078^{* *} \\
(0.032)\end{array}$ & $\begin{array}{c}0.077^{* *} \\
(0.032)\end{array}$ \\
\hline Tertiary degree & $\begin{array}{c}0.006 \\
(0.026)\end{array}$ & $\begin{array}{c}0.004 \\
(0.026)\end{array}$ & $\begin{array}{c}0.007 \\
(0.026)\end{array}$ & $\begin{array}{c}0.002 \\
(0.026)\end{array}$ \\
\hline Age & $\begin{array}{c}-0.028^{* * *} \\
(0.005)\end{array}$ & $\begin{array}{c}-0.028^{* * *} \\
(0.005)\end{array}$ & $\begin{array}{c}-0.028^{* * *} \\
(0.005)\end{array}$ & $\begin{array}{c}-0.029^{* * *} \\
(0.005)\end{array}$ \\
\hline $\operatorname{Age}^{2} \times 10^{-2}$ & $\begin{array}{c}0.030^{* * *} \\
(0.005)\end{array}$ & $\begin{array}{c}0.031^{* * *} \\
(0.005)\end{array}$ & $\begin{array}{c}0.030^{* * *} \\
(0.005)\end{array}$ & $\begin{array}{c}0.031^{* * *} \\
(0.005)\end{array}$ \\
\hline Male & $\begin{array}{c}-0.070^{* * *} \\
(0.024)\end{array}$ & $\begin{array}{c}-0.068^{* * *} \\
(0.024)\end{array}$ & $\begin{array}{c}-0.071^{* * *} \\
(0.024)\end{array}$ & $\begin{array}{c}-0.068^{* * *} \\
(0.024)\end{array}$ \\
\hline Married & $\begin{array}{c}0.317^{* * *} \\
(0.032)\end{array}$ & $\begin{array}{c}0.318^{* * *} \\
(0.032)\end{array}$ & $\begin{array}{c}0.314^{* * *} \\
(0.032)\end{array}$ & $\begin{array}{c}0.320^{* * *} \\
(0.032)\end{array}$ \\
\hline Foreigner & $\begin{array}{c}-0.168^{* * *} \\
(0.038)\end{array}$ & $\begin{array}{c}-0.167^{* * *} \\
(0.038)\end{array}$ & $\begin{array}{c}-0.165^{* * *} \\
(0.038)\end{array}$ & $\begin{array}{c}-0.170^{* * *} \\
(0.038)\end{array}$ \\
\hline Log number household members & $\begin{array}{c}-0.100^{* * *} \\
(0.032)\end{array}$ & $\begin{array}{c}-0.100^{* * *} \\
(0.032)\end{array}$ & $\begin{array}{c}-0.096^{* * *} \\
(0.032)\end{array}$ & $\begin{array}{c}-0.096^{* * *} \\
(0.032)\end{array}$ \\
\hline April interview & $\begin{array}{l}-0.029 \\
(0.024)\end{array}$ & $\begin{array}{l}-0.029 \\
(0.024)\end{array}$ & $\begin{array}{l}-0.023 \\
(0.024)\end{array}$ & $\begin{array}{l}-0.011 \\
(0.026)\end{array}$ \\
\hline Constant & $\begin{array}{l}-0.230 \\
(0.252)\end{array}$ & $\begin{array}{l}-0.227 \\
(0.248)\end{array}$ & $\begin{array}{l}-0.176 \\
(0.254)\end{array}$ & $\begin{array}{l}-0.254 \\
(0.251)\end{array}$ \\
\hline
\end{tabular}

$N=4,399$

Heteroscedasticity consistent standard errors in parentheses.

$* * * / * * / *$ significant at the $1 / 5 / 10$ percent level 
Table 4: Reported happiness, socio-economic characteristics, and reporting variables

\begin{tabular}{|c|c|c|c|}
\hline & $(1)$ & $(2)$ & $(3)$ \\
\hline Log household income & $\begin{array}{c}0.274^{* * *} \\
(0.030)\end{array}$ & $\begin{array}{c}0.423^{* * *} \\
(0.057)\end{array}$ & $\begin{array}{c}0.249^{* * *} \\
(0.034)\end{array}$ \\
\hline Employed & $\begin{array}{l}0.077^{* *} \\
(0.032)\end{array}$ & $\begin{array}{c}0.020 \\
(0.061)\end{array}$ & $\begin{array}{l}0.074^{* *} \\
(0.036)\end{array}$ \\
\hline Tertiary degree & $\begin{array}{c}0.005 \\
(0.026)\end{array}$ & $\begin{array}{l}-0.040 \\
(0.049)\end{array}$ & $\begin{array}{c}0.015 \\
(0.030)\end{array}$ \\
\hline Married & $\begin{array}{c}0.319^{* * *} \\
(0.032)\end{array}$ & $\begin{array}{c}0.265^{* * *} \\
(0.060)\end{array}$ & $\begin{array}{c}0.297^{* * *} \\
(0.037)\end{array}$ \\
\hline Response time & $\begin{array}{l}0.046^{*} \\
(0.024)\end{array}$ & & \\
\hline $\begin{array}{l}\text { Log household income } \\
\times \text { Response time }\end{array}$ & $\begin{array}{c}-0.004^{*} \\
(0.002)\end{array}$ & & \\
\hline $\begin{array}{l}\text { Employed } \\
\times \text { Response time }\end{array}$ & $\begin{array}{c}0.000 \\
(0.004)\end{array}$ & & \\
\hline $\begin{array}{l}\text { Tertiary degree } \\
\times \text { Response time }\end{array}$ & $\begin{array}{c}0.001 \\
(0.004)\end{array}$ & & \\
\hline $\begin{array}{l}\text { Married } \\
\times \text { Response time }\end{array}$ & $\begin{array}{c}0.002 \\
(0.005)\end{array}$ & & \\
\hline Cognitive effort & & $\begin{array}{c}1.912^{* * *} \\
(0.544)\end{array}$ & \\
\hline $\begin{array}{l}\text { Log household income } \\
\times \text { cognitive effort }\end{array}$ & & $\begin{array}{c}-0.222^{* * *} \\
(0.066)\end{array}$ & \\
\hline $\begin{array}{l}\text { Employed } \\
\times \text { cognitive effort }\end{array}$ & & $\begin{array}{c}0.079 \\
(0.072)\end{array}$ & \\
\hline $\begin{array}{l}\text { Tertiary degree } \\
\times \text { cognitive effort }\end{array}$ & & $\begin{array}{l}0.070 \\
(0.058)\end{array}$ & \\
\hline $\begin{array}{l}\text { Married } \\
\times \text { cognitive effort }\end{array}$ & & $\begin{array}{c}0.075 \\
(0.071)\end{array}$ & \\
\hline Background questionnaire first & & & $\begin{array}{l}-0.538 \\
(0.598)\end{array}$ \\
\hline $\begin{array}{l}\text { Log household income } \\
\times \text { Background questionnaire first }\end{array}$ & & & $\begin{array}{c}0.086 \\
(0.073)\end{array}$ \\
\hline $\begin{array}{l}\text { Employed } \\
\times \text { Background questionnaire first }\end{array}$ & & & $\begin{array}{c}0.031 \\
(0.083)\end{array}$ \\
\hline $\begin{array}{l}\text { Tertiary degree } \\
\times \text { Background questionnaire first }\end{array}$ & & & $\begin{array}{l}-0.059 \\
(0.063)\end{array}$ \\
\hline $\begin{array}{l}\text { Married } \\
\times \text { Background questionnaire first }\end{array}$ & & & $\begin{array}{c}0.113 \\
(0.075)\end{array}$ \\
\hline
\end{tabular}

$N=4,399 ; * * * / * * / *$ significant at the $1 / 5 / 10$ percent level

OLS, heteroscedasticity consistent standard errors in parentheses.

The models include in addition the variables age, age $^{2}$, male, foreigner $\log$ household members, April interwiew and their interactions with the respective reporting variables. 
Figures

Figure 1: Kernel density estimate of response time

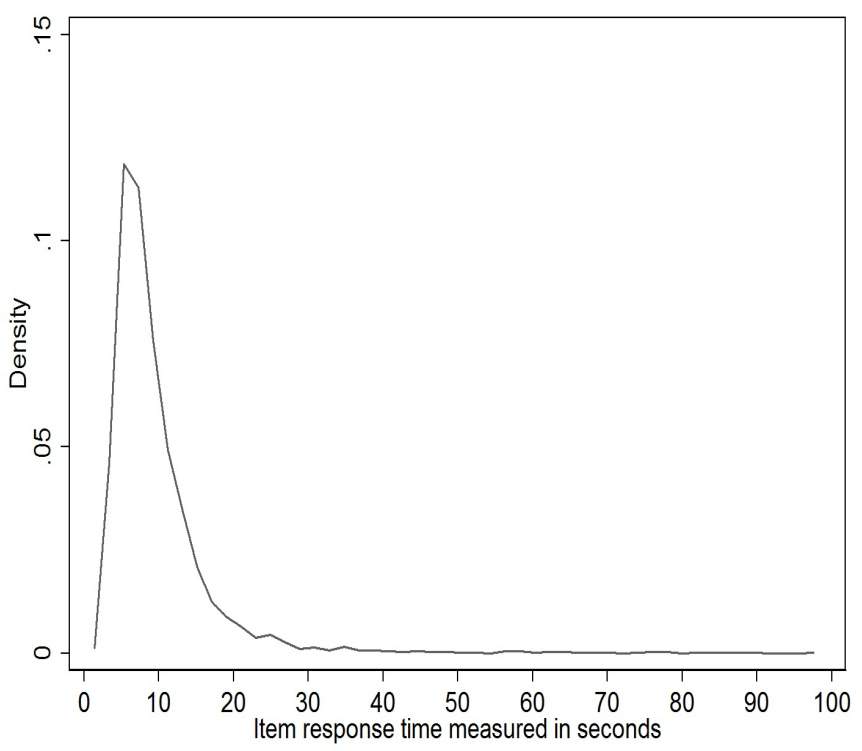




\section{Appendix A}

Screenshots of happiness questionnaire

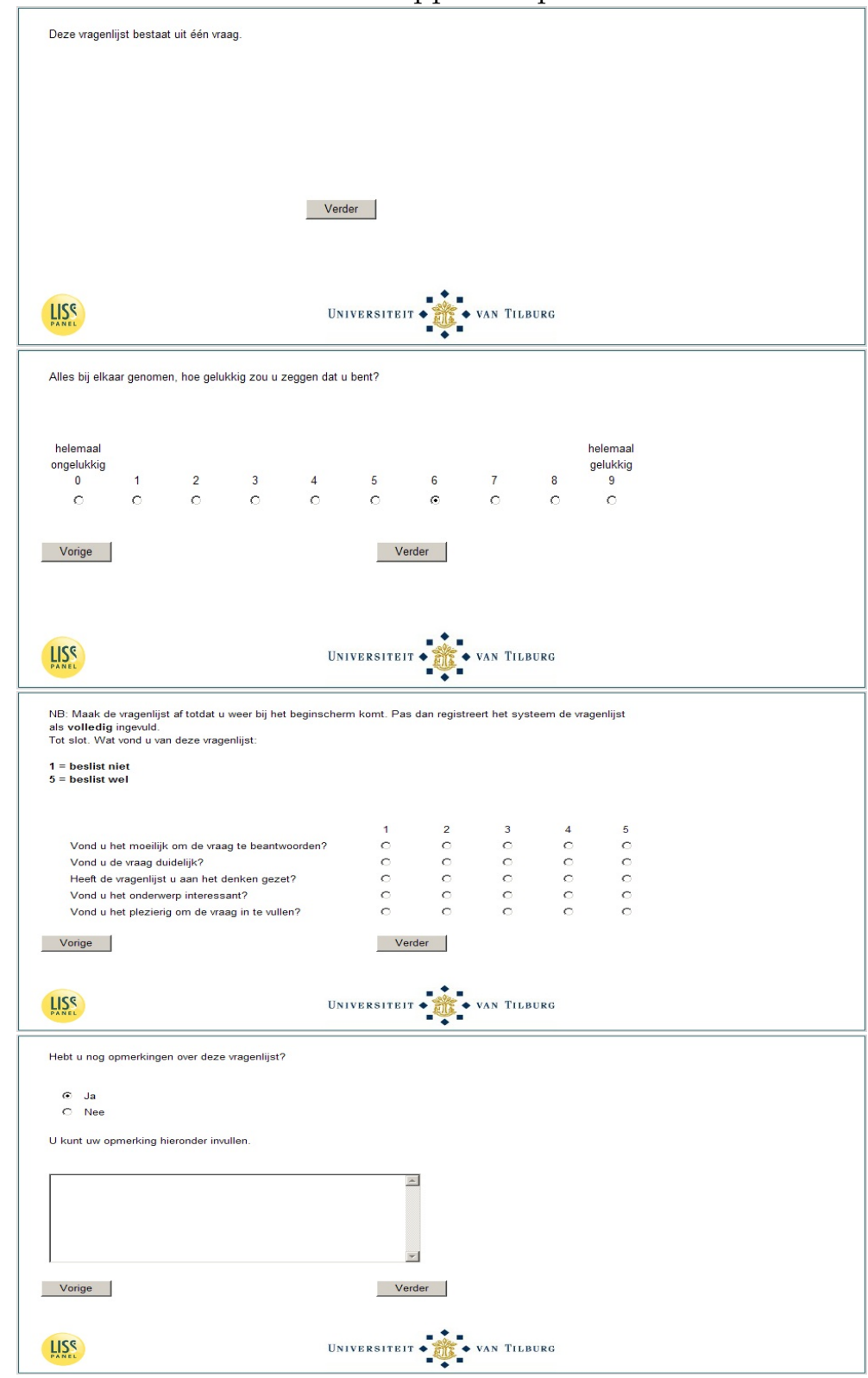

